\title{
Extranodal Follicular Dendritic Cell Sarcoma of Mesentery
}

\author{
Sachin Marda ${ }^{1}$, Venkateswara Kumar Karanam² \\ Departments of ${ }^{1}$ Surgical Oncology and ${ }^{2}$ Pathology, Yashoda Hospitals, Somajiguda, Hyderabad, India.
}

\section{Corresponding Author: \\ Dr Venkateswara Kumar Karanam \\ Email: drven.vk@gmail.com}

This is an Open Access article distributed under the terms of the Creative Commons Attribution License (creativecommons.org/ licenses/by/3.0).

Received : September 2,2020

Accepted : June 9, 2021

Published : July 10, 2021

\begin{abstract}
Background: Extranodal follicular dendritic cell sarcoma (FDCS) is a rare neoplasm. That clinically mimics a wide variety of other abdominal tumors, and correct pre-operative diagnosis is often a challenging task. Case Report: A 49-year-old female presented with abdominal pain, abdominal fullness and underwent surgical excision of mesenteric tumor which was finally diagnosed as extranodal follicular dendritic cell sarcoma of mesentery on immunohistochemistry. Conclusion: When follicular dendritic cell sarcoma is suspected histologically, immunohistochemical stains for follicular dendritic cell differentiation are performed to avoid potential misdiagnosis.
\end{abstract}

Keywords: Abdominal Neoplasms, Abdominal Pain, Follicular Dendritic Cell Sarcoma, Immunohistochemistry, Mesentery, Small Intestine.

\section{Introduction}

Follicular dendritic cell sarcoma (FDCS), a neoplasm with follicular dendritic cell differentiation, was first characterised by Monda et al. in 1986 [1]. Although FDCS is a rare tumor, it generally occurs in lymph nodes, most commonly, the cervical, mediastinal, or axillary lymph nodes. In fewer than one third of cases, FDCS can also be found in extranodal sites, including the tonsils, nasopharynx, pancreas, liver, peri-pancreatic and peritoneal tissues. FDC sarcoma with an extra nodal origin is extremely rare. The diagnosis of FDC sarcomas is based on node-based spindle cell lesions, and the expression of CD21, CD35 and Clusterin [2]. This case report focuses on one more case of this rare tumor occurring in the mesentery. We are reporting this case in view of the rarity of this malignancy and the importance of immunohistochemistry (IHC) in the diagnosis of gastrointestinal malignancy to avoid inappropriate treatment practices.

\section{Case Report}

A 49-year-old post-menopausal female presenting with abdominal painless mass, abdominal discomfort, decreased appetite for approximately 3 months was admitted to our hospital. There was no history of fever, vomiting, melena, constipation, weight loss and loss of appetite. On examination of abdomen there was $10 \times 8 \mathrm{~cm}$ firm swelling in the umbilical region which is freely mobile horizontally and has restricted mobility in the vertical direction. It was non tender and dull to percussion. All lab reports including CA 125 were normal.

The axial contrast-enhanced computed tomographic (CT) scan showed a large well defined intra-abdominal mass, exhibiting heterogeneous enhancement and marked necrosis [Fig.1]. The coronal reconstruction $\mathrm{CT}$ image and sagittal section revealed the size, contour and location of the tumor [Fig.2,3]. Fine-needle aspiration cytology showed spindle cell neoplasm. Exploratory laparotomy was done showing hard lump arising in the small bowel mesentery [Fig.4]. Enbloc resection of mass along with involved segment of bowel followed by resection and stapler anastomosis was done [Fig.5,6]. Post-operative period was uneventful and patient discharged in 5 days. The final histopathology with immunohistochemistry 
(IHC) confirmed as follicular dendritic cell sarcoma. Microscopic sections from mass showed spindle cells arranged in storiform pattern admixed with lymphoplasmacytic cells. CD21 and CD35 were diffusely and strongly positive [Fig.7]. S100 protein shows scattered positivity; ckit, DOG1, SMA, CD34, LCA, CD 23 and ALK1 were negative. Patient has no symptoms and no metabolically active lesion was present anywhere in the body at one year of follow-up.

\section{Discussion}

Extranodal FDC sarcoma was first reported by Chan et al. in 1994 in head and neck cases [3]. DC sarcoma is an uncommon neoplasm of antigen presenting cells of the B-cell follicles of lymphoid organs. Follicular dendritic cells are required for germinal centres of B-cell follicles, which are present not only in lymph nodes but also extranodally, either as acquired lymphoid tissue or as part of the organised constitutive lymphoid tissue. Its identity remained unknown until recently. Therefore, perhaps there are more FDCS cases than those that have been reported. Although FDCS can occur at any age, it usually affects young adults. A review of the literature showed a slight female predominance [4].

The most common clinical presentation is that of a painless, slow growing swelling [5]. Imaging can be an initial tool for diagnosis and staging. Smaller homogeneous masses are usually seen on CT scan; however, heterogeneity as a result of necrosis or hemorrhagic areas have been reported in $80 \%$ of cases [6]. Pathological diagnosis cannot be based solely on morphological grounds but must be confirmed by IHC and preferably supported by ultrastructural studies. Most widely used FDCS markers are CD21, CD23, CD35, and D2-40 (podoplanin), which can distinguish FDCS from other spindle-cell neoplasms [4,7,8]. Recently, two novel, highly sensitive and specific markers for FDCS, follicular dendritic cell-secreted protein and serglycin, have been identified [9]. Awareness

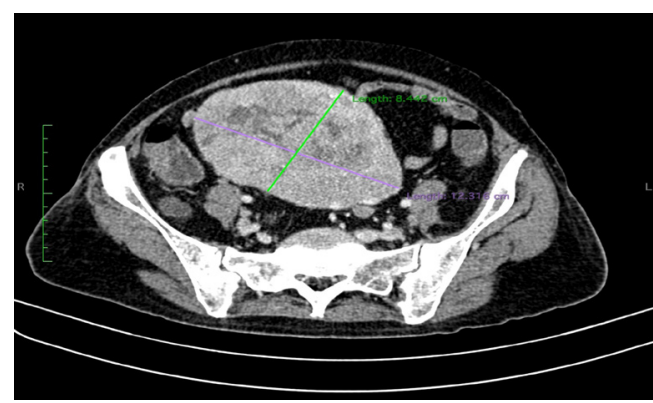

Fig.1: The enhanced multiphase CT axial image showing marked heterogeneous enhancement with areas of necrosis.

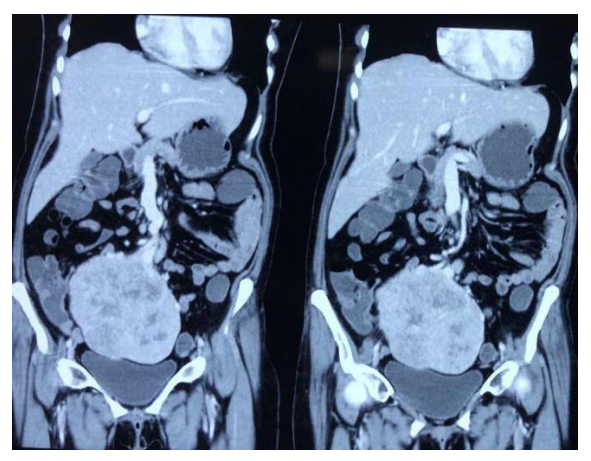

Fig.2: CT coronal image showing tumor originating in mesentery and surrounded by small bowel.

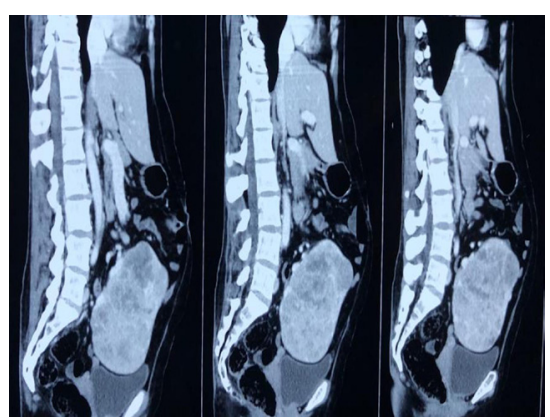

Fig.3: CT sagittal section image showing the extent of tumor in abdomen.

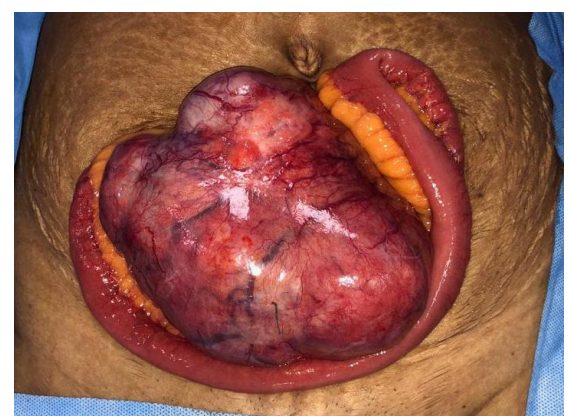

Fig.4: Intraoperative image showing the tumor in the mesentery of small bowel. 
of FDCS and the ability to recognize this tumor are important, because the tumor closely mimics a wide variety of other tumors and tumor-like lesions. Often, FDCS is not considered in the differential diagnosis, especially when they occur in extranodal sites. Even with immunohistochemical studies, the diagnosis of FDCS may be missed because FDC markers are not included among the routine panel of antibodies used for the investigation of undifferentiated neoplasms.

Surgical resection is considered to be an effective clinical treatment for FDCS. The survival rate of surgical resection for non-metastatic cases is significantly higher than non-operative therapy. The therapeutic effect of adjuvant chemotherapy and radiotherapy is unclear due to its rarity. Thus, FDCS treatment should be adjusted according to the specific invasion of the tumor, age of patient, location, size, mitotic count, presence of significant necrosis and cellular atypia of the tumor $[2,10]$.

\section{Conclusion}

FDC remains under-recognised and misdiagnosis is common. With the aid of immunohistochemical analysis and the two most reliable follicular dendritic cell markers, CD21 and CD35, the diagnostic accuracy has been significantly improved. Therefore, when FDCS is suspected histologically, immunohistochemical stains for follicular dendritic cell differentiation should be performed to avoid potential misdiagnosis.

Contributors: SM: manuscript editing, patient management; VKK: manuscript writing, patient management. VKK will act as guarantor. Both authors approved the final version of this manuscript and are responsible for all aspects of this study.

Funding: None; Competing interests: None stated.

\section{References}

1. Monda L, Warnke R, Rosai J. A primary lymph node malignancy with features suggestive of dendritic reticulum cell differentiation. A report of 4 cases. American J Pathol. 1986;122(3):562-572.

2. Shia J, Chen W, Tang LH, Carlson DL, Qin J, Guillem $\mathrm{JG}$, et al. Extranodal follicular dendritic cell sarcoma: Clinical, pathologic, and histogenetic characteristics of

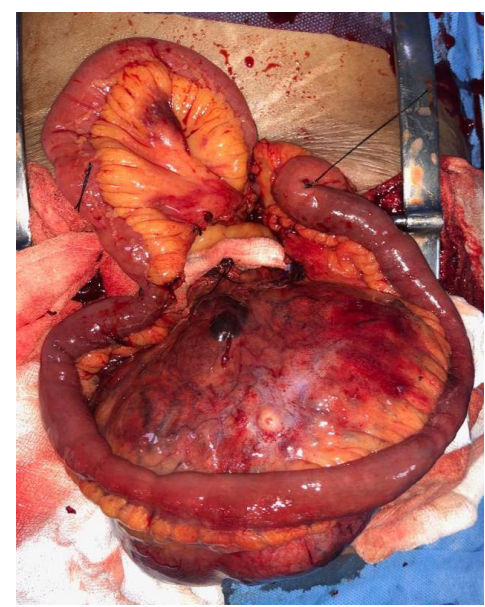

Fig.5: Intraoperative image showing the tumor after ligating the feeding vessels.

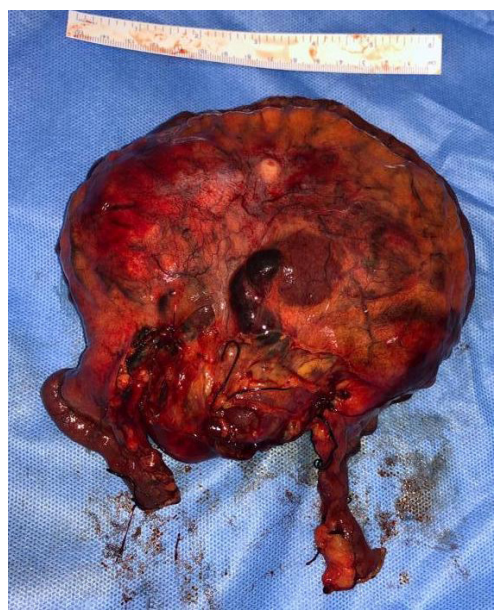

Fig.6: Enbloc resection specimen along with involved part of small bowel.

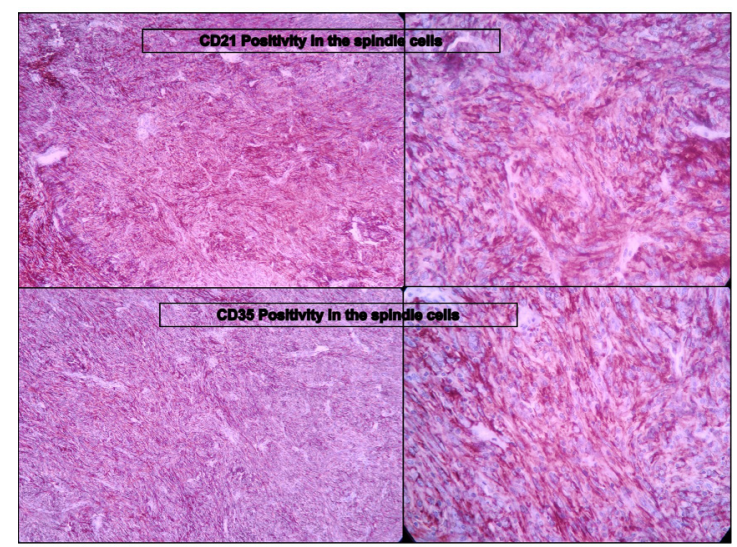

Fig.7: IHC picture showing CD21 and CD35 positivity in spindle cells. 
an underrecognized disease entity. Virchows Archiv. 2006;449(2):148-158.

3. Chan JKC, Tsang WYW, Ng CS, Tang SK, Yu HC, Lee AWM. Follicular dendritic cell tumors of the oral cavity. American J Surgical Pathol. 1994;18(2):148-157.

4. Wang RF, Han W, Qi L, Shan LH, Wang ZC, Wang LF. Extranodal follicular dendritic cell sarcoma: A clinicopathological report of four cases and a literature review. [Online] Oncology Letters. Spandidos Publications; 2015. pp. 391-398.

5. Kairouz S, Hashash J, Kabbara W, Mchayleh W, Tabbara IA. Dendritic cell neoplasms: An overview. American J Hematol. 2007;82:924-928.

6. Li J, Geng ZJ, Xie CM, Zhang XK, Chen RY, Cai PQ, et al. Computer tomography imaging findings of abdominal follicular dendritic cell sarcoma. Medicine (Baltimore). 2016;95(1):e2404.
7. Chan JKC, Tsang WYW, Ng CS. Follicular dendritic cell tumor and vascular neoplasm complicating hyalinevascular Castleman's disease. American J Surgical Pathol. 1994;18(5):517-525.

8. Hollowood K, Stamp G, Zouvani I, Fletcher CD. Extranodal follicular dendritic cell sarcoma of the gastrointestinal tract. morphologic, immunohistochemical and ultrastructural analysis of two cases. Am J Clin Pathol. 1995;103(1):90-97.

9. Dutta A, Arun P, Roy P, Arun I. Cytological diagnosis of follicular dendritic cell sarcoma: A case report and review of literature. Cytopathology. 2018;29(5):461-467.

10. Xin Z, Kong D. Clinicopathologic profile of extranodal follicular dendritic cell sarcoma in the mesentery of small intestine: a study of two cases with literature review. International Journal of Clinical and Experimental Pathology. 2018;11(5):2372-2376. 